\title{
A multi-objective optimization of closed-loop supply chain problem with vehicle routing
}

\author{
Shahul Hamid Khan 1, ${ }^{*}$, Vivek Kumar Chouhan ${ }^{1}$, Santhosh Srinivasan ${ }^{2}$ \\ ${ }^{1}$ Department of Mechanical Engineering, Indian Institute of Information Technology, Design and Manufacturing, \\ Kancheepuram (IIITDM), Chennai, India. \\ 2 Department of Mechanical Engineering, Sri Krishna College of Technology, Coimbatore, India
}

Global Journal of Engineering and Technology Advances, 2021, 06(02), 121-130

Publication history: Received on 05 January 2021; revised on 30 January 2021; accepted on 02 February 2021

Article DOI: https://doi.org/10.30574/gjeta.2021.6.2.0009

\begin{abstract}
Product recovery has become significant business strategies to increase a competitive edge in business and also in the society. Parts from discarded products due to rapid advancement and post-consumer products before \& after end-oflife (EOL) are recovered to reduce landfill waste and to have become a part of circular economy. Product recovery is made possible with the help of Closed-loop supply chain (CLSC). This paper concentrates on multi-period, multiproduct, and multi-echelon Closed Loop Green Supply Chain (CLGSC) network. A bi-objective (cost and emission) Mixed Integer Linear Programming (MILP) model has been formulated for the network and has been optimized using Goal Programming approach and Genetic Algorithm. Results are discussed for providing some managerial insights of the model.
\end{abstract}

Keywords: Closed Loop Supply Chain; Product Recovery; Goal Programming; Emission; Vehicle Routing; Green Supply Chain

\section{Introduction}

Product recovery is made possible with the help of CLSC. Researchers and practitioners are keen on solving CLSC, Green Supply Chain (GSC), Remanufacturing, CO2 saving rate and Travelling Salesman Problem (TSP) models as Green has become more popular. Recapturing value from End-of-Use (EOU) and EOL product and related information from the customer to the manufacturer is known as Reverse Logistics (RL) (Rogers and Tibben - Lembke, 1998). Due to legislative, environmental and economic reasons, the importance of RL has amplified considerably in the last two decades (Ritichie et al., 2000). Value recovering as much as possible is the use of RL (EISaadany et al., 2013) and reduce the extraction of virgin materials and solid waste dumps. (Bonney and Jaber, 2011; Matar et al., 2014). Dell has developed an RL by which the products are refurbished or purchase fresh parts easily (Kumar and Craig, 2007). CLSC has two parts, Forward Logistics (FL) and Reverse Logistics. RL has become a fundamental part of Green Supply Chain Management. It exists in different industries including electronics, basic materials, and others. Increased customer's awareness and concern for the environment, the products that are not environmentally friendly are given less importance and it is used to fill warranty pools of sold products by refurbishing, and the remaining are sold in secondary markets (Krikke et al., 2004). Remanufacturing is a popular research topic among researchers and practitioners in developing countries due to resource scarcity (Rashid et al., 2013). Remanufactured products will result in less greenhouse emission over virgin manufacturing practices with less consumption of energy and cost (Sutherland et al., 2008). The researchers also interested in building the low-carbon supply chain. CO2 emission in the supply chain beyond single organization is reduced and visualized. Many studies proposed by extending the classical Vehicle Routing

\footnotetext{
* Corresponding author: Shahul Hamid Khan

Department of Mechanical Engineering, Indian Institute of Information Technology, Design and Manufacturing, Kancheepuram (IIITDM), Chennai, India.
} 
Problem (VRP) and TSP objectives environmental and social impacts can be reduced (McKinnon \& Piecyk, 2009; Sbihi \&Eglese, 2007; Bektas \& Laporte, 2011). As there is a need to extend the life of EOL products and to balance various environmental pressures, companies have to develop a system that avoids landfills (Rathore et al., 2011). The first sector to implement remanufacturing is the automobile sector (Seitz, 2007) for EOL vehicles with strategies like repair, reconditioning or reuse with warranties equivalent to a new product with better quality, new appearance, upgraded parts and original specifications (Ijomah, 2002 and Ijomah et al, 2007). Remanufacturing has become popular in other sectors especially in electronic industries where the EOL and a premature product is more. But in developing countries, remanufacturing is still in the initial stages and still struggling with remanufacturing implementation (Kannan et al., 2016).

The contributions of this paper are as follows. (1) developing a multi-objective, multi-period, and multi-part \& product MILP model to optimize the integrated location-allocation-emission reduction planning for a CLGSC network with TSP between distribution hubs and retailers; (2) Purchasing and reprocessing costs are considered to manage the realistic trade-off problem; (3) results from the computational experiments used to analyze various performance components and some managerial insight for the proposed model through a sample problem instance.

The outline of this report is as follows. Problem definition is presented in section 2. Section 3, the mathematical model is presented. The data description, solution methodology is presented in section 4, and results are presented in section 5. Computation Experiment in section 6. Section 7 presents the conclusions and future scope.

\section{Problem definition}

From the literature, the major objective framed was to design and optimize a multi-objective, multi-product, multiperiod CLGSC network. A real life CLGSC network is presented in this section and it composed of suppliers, processing units, assembling units, distribution hubs, retailers, Sorting and dismantling units, and reprocessing units as shown in Figure 1. Vehicle routing is done between distribution hubs and retailers. Two products are used to flow in the CLGSC network (Santhosh Srinivasan and Shahul Hamid Khan, 2016a).

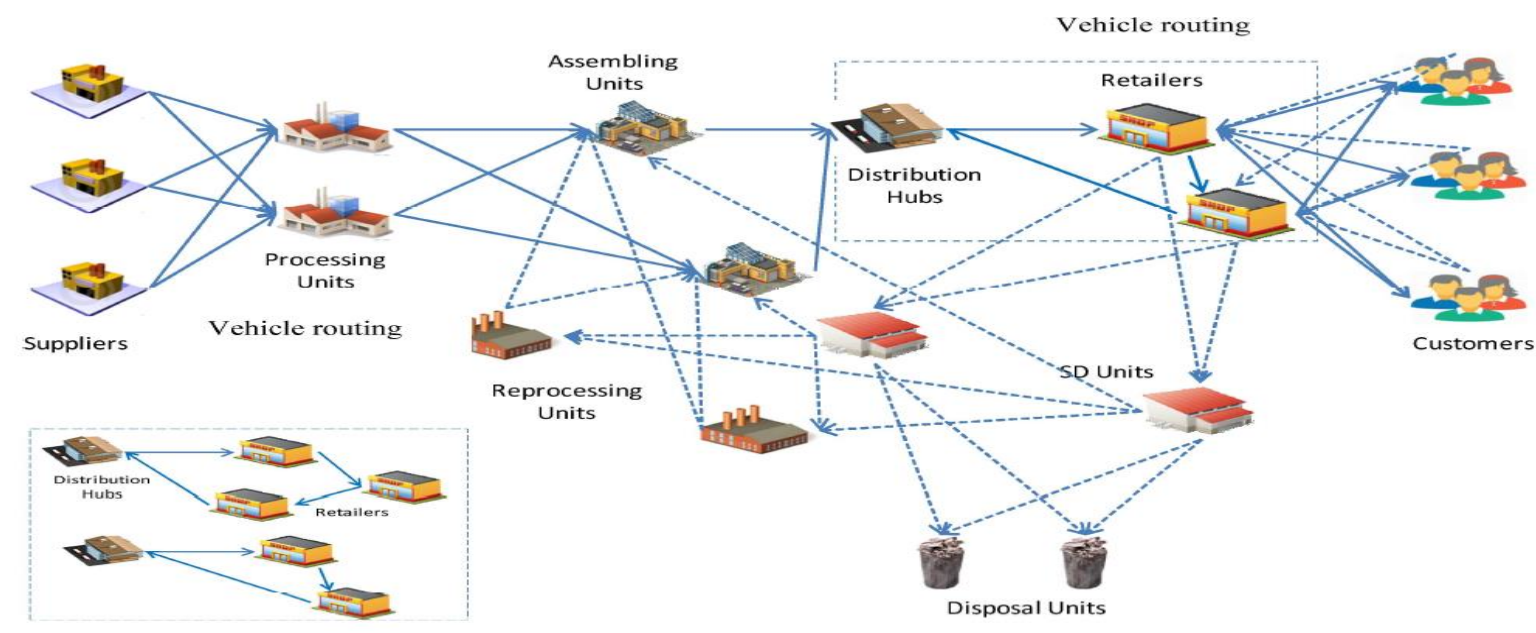

Figure 1 Proposed Closed Loop Supply Chain

\section{Mathematical formulation}

\subsection{Variables}
$Q S_{i l p}^{m}$
Quantity shipped from Supplier l to Processing Unit $\mathrm{p}$ for Raw Material i in period m
$Q P^{n}{ }_{j p a}$
Quantity shipped from Processing Unit $\mathrm{p}$ to Assembling Unit a for Part $\mathrm{j}$ in period $\mathrm{m}$
$Q A_{k a n}^{m}$
Quantity shipped from Assembling a to Distribution Hub $\mathrm{n}$ for Product $\mathrm{k}$ in period $\mathrm{m}$ 
$Q N_{k d t}^{m} \quad$ Quantity shipped from node d to t belonging to q cluster connected to $\mathrm{n}$ Distribution Hub in period $\mathrm{m}$

$Q C_{k r c}^{n} \quad$ Quantity shipped from Retailer r to Customer c for Product k in period m

$Q F_{k c r}^{m} \quad$ Quantity shipped from Customer c to retailer $\mathrm{r}$ for Product k in period $\mathrm{m}$

$Q R_{k r w}^{n} \quad$ Quantity shipped from Retailer r to SD Unit w for Product k in period m

$Q Y_{j w y}^{m} \quad$ Quantity shipped from SD Unit w to Disposal Unit y for Part j in period m

$Q W_{j w x}^{m}$ Quantity shipped from SD Unit w to Reprocessing Unit x for Part j in period m

$Q Z_{j w a}^{m} \quad$ Quantity shipped from SD Unit w to Assembling Unit a for Part j in period m

$Q X_{j x a}^{m} \quad$ Quantity shipped from Reprocessing Unit x to Assembling Unit a for Part j in period m

$U P_{p}^{m} \quad$ If the Processing Unit $\mathrm{p}$ is open in period $\mathrm{m}, 1$; otherwise, 0

$U A_{a}^{m} \quad$ If the Assembling Unit a is open in period m, 1; otherwise, 0

$U N_{n}^{m} \quad$ If the Distribution Hub n is open in period m, 1; otherwise, 0

$U R_{r}^{m} \quad$ If the Retailer $\mathrm{r}$ is open in period m, 1; otherwise, 0

$U W_{w}^{m}$ If the SD Unit w is open in period m, 1; otherwise, 0

$U X_{x}^{m} \quad$ If the Reprocessing unit $\mathrm{x}$ is open in period $\mathrm{m}, 1$; otherwise, 0

$U Y_{y}^{m} \quad$ If the Disposal Unit $\mathrm{n}$ is open in period $\mathrm{m}, 1$; otherwise, 0

$T S R_{d t n}^{q}$ If vehicle travel from node $\mathrm{d}$ to $\mathrm{t}$ belonging to q cluster connected to $\mathrm{n}$

Distribution Hub, 1; $\quad$ otherwise, 0

$T N R_{n}^{q}$ If $\mathrm{n}$ Distribution Hub is connected to q Cluster, 1 ; otherwise, 0

\subsection{Parameters}
$C S_{i l}^{m} \quad$ Capacity of Supplier $\mathrm{l}$ in period $\mathrm{m}$
$C P_{j p}^{n} \quad$ Capacity of Processing Unit $\mathrm{p}$ in period $\mathrm{m}$
$C A_{k a}^{m} \quad$ Capacity of Assembling Unit a in period $\mathrm{m}$
$C N_{k n}^{m} \quad$ Capacity of Distribution Hub $\mathrm{n}$ in period $\mathrm{m}$
$C R_{k r}^{m} \quad$ Capacity of Retailer $\mathrm{r}$ in period $\mathrm{m}$
$C W_{j w}^{m} \quad$ Capacity of Sorting and Dismantling Unit w in period $\mathrm{m}$
$C X_{j x}^{m} \quad$ Capacity of Reprocessing Unit x in period m
$S I_{i j} \quad$ Stake of Raw Material i in Part j
$S J_{j k} \quad$ Stake of Part j in Product k
$\operatorname{dem}_{k c}^{m} \quad$ Demand of Customer c in period $\mathrm{m}$ 
$f_{p}^{o}$

$f_{a}^{o}$

$f_{n}^{o}$

$f_{w}^{o}$

$f_{x}^{o}$

$f_{y}^{o}$

$f_{i l}$

\section{$f_{j p}$}

$f_{k a}$

$f_{k n}$

$f_{k w}$

$f_{j y}$

$$
f_{j x}
$$

$f e$.

$f e_{j p}$

$f e_{k a}$

$f e_{k w}$

$f e_{j y}$

$f e_{j x}$

Emission while reprocessing of Part $\mathrm{j}$ in Reprocessing Unit $\mathrm{x}$

$T A_{k a n} \quad$ The unit cost of shipping from Assembling Unit a to Distribution Hub $\mathrm{n}$ for Product k

$T N_{k d t}$ Shipping cost between the nodes $\mathrm{d}$ and $\mathrm{t}$ belonging to the $\mathrm{q}$ cluster Connected to the $\mathrm{n}$ Distribution Hub for product $\mathrm{k}$

$T R_{k r w} \quad$ Shipping cost per unit from Retailer $\mathrm{r}$ to SD Unit $\mathrm{w}$ for Product $\mathrm{k}$

$T Y_{j w y}$ Shipping cost per unit from SD Unit w to Disposal Unit y for Product $\mathrm{k}$

$T W_{j w x}$ Shipping cost per unit from SD Unit $\mathrm{w}$ to Reprocessing Unit $\mathrm{x}$ for Product $\mathrm{k}$

$T Z_{\text {jwa }} \quad$ Shipping cost per unit from SD Unit $\mathrm{w}$ to Assembling Unit a for Product $\mathrm{k}$

$T E A_{k a n}$ Shipping emission per unit from Assembling Unit a to Distribution Hub $\mathrm{n}$ for Product k

$T E N_{k n r}$ Shipping emission per unit from Distribution Hub $\mathrm{n}$ to Retailer $\mathrm{r}$ for Product $\mathrm{k}$

$T E R_{k r w}$ Shipping emission per unit from Retailer $\mathrm{r}$ to SD Unit $\mathrm{w}$ for Product $\mathrm{k}$

$T E Y_{\text {jwy }}$ Shipping emission per unit from SD Unit w to Disposal Unit y for Product $\mathrm{k}$ 
$T E W_{j y x}$ Shipping emission per unit from SD Unit w to Reprocessing Unit x for Product k

$T E Z_{\text {jwa }}$ Shipping emission per unit from SD Unit w to Assembling Unit a for Product $\mathrm{k}$

$T S P_{q} \quad$ Total number of nodes in the q cluster

$E_{d} \& E_{t}$ Positive values that ensure no sub-routing in TSP

$\eta \quad$ Percentage of demand, which is collected by Retailer from Customer

$\lambda \quad$ Percentage of disassembled amount which is disposed

$v \quad$ Percentage of disassembled amount resend to Assembling Unit

\subsection{Objective Functions}

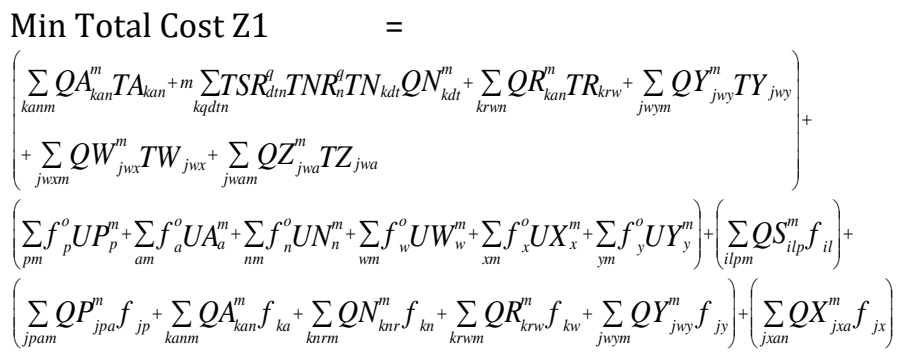

Min Total Emission Z2 =

$$
\begin{aligned}
& \left(\begin{array}{l}
\sum_{k a n m} Q A_{k a n}^{m} T E A_{k a n}+\sum_{k n r m} Q N_{k n r}^{m} T E N_{k n r}+\sum_{k r w n} Q R_{k a n}^{m} T E R_{k r w}+\sum_{j w y m} Q Y_{j w y}^{m} T E Y_{j w y}+ \\
\sum_{j w x m} Q W_{j w x}^{m} T E W_{j w x}+\sum_{j w a m} Q Z_{j w a}^{m} T E Z_{j w a}
\end{array}\right)+ \\
& \left(\sum_{j p a m} Q P_{j p a}^{m} f e_{j p}+\sum_{k a n m} Q A_{k a n}^{m} f e_{k a}+\sum_{k r w m} Q R_{k r w}^{m} f e_{k w}+\sum_{j w m} Q Y_{j w y}^{m} f e_{j y}+\sum_{j x a n} Q X_{j x a}^{m} f e_{j x}\right)
\end{aligned}
$$

Constraints

$$
\begin{aligned}
& \sum_{p} Q S_{i l p}^{m} \leq C S_{i l}^{m}, \forall i, l, m \\
& \sum_{a} Q P_{j p a}^{n} \leq C P_{j p}^{n} U P_{p}^{n}, \forall j, p, m \\
& \sum_{n} Q A_{k a n}^{m} \leq C A_{k a}^{m} U A_{a}^{m}, \forall k, a, m \\
& \sum_{r} Q N_{k n r}^{m} \leq C N_{k n}^{m} U N_{N}^{m}, \forall k, n, m \\
& \sum_{w} Q R_{k r w}^{n}+\sum_{c} Q C_{k r c}^{n} \leq C R_{k r}^{m} U R_{r}^{m}, \forall k, r, m \\
& \sum_{y} Q Y_{j w y}^{m}+\sum_{x} Q W_{j w x}^{m}+\sum_{a} Q Z_{j w a}^{m} \leq C W_{j w}^{m} U W_{w}^{m}, \forall j, w, m \\
& \sum_{a} Q X_{j x a}^{m} \leq C X_{j x}^{m} U X_{x}^{m}, \forall j, x, m \\
& \sum_{r} Q C_{k r c}^{n} \geq d e m_{k c}^{m}, \forall k, c, m \\
& \sum_{l} Q S_{i l p}^{m}-\left(\sum_{j} Q P_{j p a}^{n}\right) * S I_{i j}=0, \forall i, p, a, m \\
& \sum_{p} Q P_{j p a}^{m}+\sum_{w} Q Z_{j w a}^{m-1}+\sum_{x} Q X_{j x a}^{m-1}-\left(\sum_{k} Q A_{k a n}^{m}\right) * S J_{j k}=0 \quad \forall j, a, n, m \\
& \sum_{a} Q A_{k a n}^{m}-\sum_{r} Q N_{k n r}^{m}=0, \forall k, n, m \\
& \sum_{n} Q N_{k n r}^{m}+\sum_{c} Q F_{k c r}^{m}-\sum_{c} Q C_{k r c}^{n}-\sum_{w} Q R_{k r w}^{n}=0, \forall k, r, m \\
& \left(\lambda \sum_{r} Q R_{k r w}^{m}\right) * S J_{j k}-\sum_{y} Q Y_{j w y}^{m}=0, \forall k, w, m
\end{aligned}
$$




$$
\begin{aligned}
& \left(v \sum_{r} Q R_{k r w}^{n}\right) * S J_{j k}-\sum_{a} Q Z_{j w a}^{m}=0, \forall k, w, m \\
& \left\{(1-v-\lambda) \sum_{r} Q R_{k r w}^{m}\right\}^{*} S J_{j k}-\sum_{x} Q W_{j w x}^{m}=0, \forall j, k, w, m \\
& \sum_{w} Q W_{j w x}^{m}-\sum_{a} Q X_{j x a}^{m}=0, \forall j, x, m \\
& \sum_{d} T S R_{d t n}^{q}=0, \forall t<T S P^{q}, n, q, d \neq t \\
& \sum_{t} T S R_{d t n}^{q}=0, \forall t<T S P^{q}, n, q, d \neq t \\
& \sum_{d} T S R_{d t n}^{q}-\sum_{d} T S R_{t d n}^{q}=0, \forall t<T S P^{q}, n, q, d \neq t \\
& \sum_{d} T N R_{n}^{q} \sum_{d} T S R_{d t n}^{q}=1, \forall t, q, d \neq t \\
& \left\lfloor E_{d}-E_{t}+\operatorname{TSP}^{q} \operatorname{TSR}_{d t n}^{q}=\operatorname{TSP} P^{q}-1\right\rfloor
\end{aligned}
$$

The objectives are to minimize total cost (TC) and total emission (TE) in the supply chain. The total cost objective has five components. Total transportation cost (TrC) of CLGSC network is represented is the first component, the setup cost (SC) of different facilities in the chain is the second component, the logistics cost (LC) of the chain is the third component, raw material purchase cost (RPC) of the chain is the fourth component and reprocessing cost (RC) of the chain is the final component. Similarly, total emission has two components. Total transportation emission (TrE) of CLGSC network is presented in the first component and total logistics emission (LE) is presented in the second component. Constraints (03)-(09) ensure that the production and transportation amount must not surpass the capacity of all the facilities respectively. Constraint (10) ensures that demands fully satisfied for both the products. Constraints (11) - (18) are the balance equations for the forward and reverse facilities. Constraints (19) - (23) are the vehicle routing equations between Distribution Hubs and Retailers. Constraint (24) enforces the positivity of decision variables. Finally, Constraint (25) represents the binary variables (Santhosh Srinivasan and Shahul Hamid Khan, 2016b).

\section{Solution methodology}

In this section, a new Genetic Algorithms is proposed to solve the model. Before solving the problem, the multiple objectives were converted into a single objective to find an efficient solution. A pre-emptive method can be used when the model has several objectives with different priorities. Combined Objective Function COF $=\mathrm{w} 1 * \mathrm{Z} 1+\mathrm{w} 2 * \mathrm{Z} 2$

The new proposed Genetic Algorithms is as follows:

Step 1: Generate an initial population which must satisfy all constraints. Population size is 50.

Step 2: Calculate the objective values of chromosomes in the population

Step 3: Evaluate fitness: For this minimization problem, the fitness function is an equivalent maximization problem chosen, such that optimum point remains unchanged.

\section{Step 4: Selection:}

The roulette wheel selection is used. The probability of selecting the ith string was explained in Wang et al 2010.

Step 5: Crossover: The Random cut two point crossover is used, here the two cutting point is randomly fixed in each generation. The Probability of crossover is 0.8 .

Step 6: Inverse Mutation: here the bits are entirely reversed with respect to parent bits. Probability of mutation is 0.1

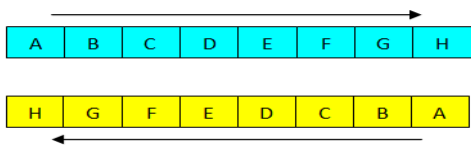


Step 7: Elite strategy: The elite strategy keeps the fit chromosomes from the previous generation into the next generation. The elite size is 4 .

Step 8: Replacement: The new population generated in accordance with the above-mentioned steps updates the old population.

Step 9: Stopping rule. If the number of generations equals 500 then stop, otherwise go to Step 1.

\section{Computational experiments}

In this section, the result of a realistic proposed CLGSC network problem for random instances are illustrated. Computational properties and complexities of solving the problem are studied. Some insights are provided for the model based on different scenarios. The network constitutes a sample problem of 5 suppliers, 3 processing units, 2 assembling units, 2 distribution hubs, 4 retailers, 2 SD units, 1 reprocessing unit, and 1 disposal unit. Five kinds of ram material that have different utilization rate are supplied by suppliers, which in turn, are converted into four parts in processing units (Santhosh Srinivasan and Shahul Hamid Khan, 2018).

Table 1 Parameters and Values

\begin{tabular}{|l|l|l|l|}
\hline Parameters & Intervals & Parameters & Intervals \\
\hline$C S_{i l}^{m}$ & 40000 & Distance between $\mathrm{l}$ and $\mathrm{p}$ & $200-300$ \\
\hline$C P_{j p}^{m}$ & 40000 & Distance between $\mathrm{p}$ and a & $130-150$ \\
\hline$C A_{k a}^{m}$ & 5000 & Distance between a and $\mathrm{n}$ & $60-100$ \\
\hline$C N_{k n}^{m}$ & 5000 & Distance between $\mathrm{n}$ and $\mathrm{r}$ & $60-80$ \\
\hline$C R_{k r}^{m}$ & 3000,2000 & Distance between $\mathrm{r}$ and $\mathrm{w}$ & $60-80$ \\
\hline$C W_{j w}^{m}$ & 3000 & Distance between $\mathrm{w}$ and a & $140-200$ \\
\hline$f_{i l}$ & Uniform (6-10) & Distance between x and a & $125-150$ \\
\hline$f_{j p}$ & Uniform (22-29) & Distance between $\mathrm{r}$ and $\mathrm{r}$ & $60-80$ \\
\hline$f_{k a}$ & Uniform (12-14) & Return Rate $\eta$ & 0.1 \\
\hline$f_{j x}$ & Uniform (12-18) & $f e_{j y}$ & Uniform (2-7) \\
\hline$f e_{j p}$ & Uniform (10-15) & $f e_{j x}$ & Uniform (10-15) \\
\hline
\end{tabular}

These four parts are assembled into two products in assembling units. Road transportation is used for shipping products, parts, and raw materials from different facilities. The transportation cost and emission is given as 20 Rs per ton-Km and 20 gm per ton-Km for a general truck. The fixed cost is found to be 200000 Rs, 100000 Rs, 50000 Rs, 75000 Rs, 75000 Rs and 50000 Rs for processing units, assembling units, distribution hubs, sorting and dismantling units, reprocessing units, and disposal units respectively (Vivek Kumar Chouhan et al 2020). The required parameter values are given in Table 1. The MILP formulation (1) - (25) of the sample instances will be computed on a PC with an Intel i7 $2.54 \mathrm{GHz}$ processor with $8 \mathrm{~GB}$ RAM.

\section{Results and Discussions}

Table 2 gives the Cost Performance Criteria (CPC) as a percentage of the objective 1 function value and Emission Performance Criteria (EPC) as a percentage of the objective 2 function values considering both Z1 \& Z2. From Table 2 it is clear that purchasing cost and Logistics cost dominates the Total cost. Setup cost and reprocessing cost does not contribute more. Whenever the percentage of return product increases then Purchasing cost decreases and Reprocessing cost is increased. Table 3 shows the optimal and feasible solution for different problem size. 
Table 2 Cost performance components and Emission performance components

\begin{tabular}{|c|c|c|c|c|c|c|c|c|c|c|c|}
\hline & \multirow[b]{2}{*}{ CPC } & \multicolumn{2}{|l|}{ GP } & \multicolumn{2}{|l|}{ NGA } & & \multirow[b]{2}{*}{ EPC } & \multicolumn{2}{|l|}{ GP } & \multicolumn{2}{|l|}{ NGA } \\
\hline & & Value (Rs) & $\begin{array}{l}\% \text { of Total } \\
\text { Cost }\end{array}$ & Value (Rs) & $\begin{array}{l}\% \text { of Total } \\
\text { Cost }\end{array}$ & & & $\begin{array}{l}\text { Value } \\
\text { (grams) }\end{array}$ & $\begin{array}{l}\% \text { of Total } \\
\text { Emission }\end{array}$ & $\begin{array}{l}\text { Value } \\
\text { (grams) }\end{array}$ & $\begin{array}{l}\% \text { of Total } \\
\text { Emission }\end{array}$ \\
\hline C1 & $\mathrm{TC}$ & 16611335 & 100.00 & 17008346 & 100.00 & P1 & $\mathrm{TE}$ & 4607672 & 100.00 & 4708613 & 100.00 \\
\hline $\mathrm{C} 2$ & SC & 3600000 & 21.67 & 3650000 & 21.46 & P2 & $\operatorname{TrE}$ & 1781935 & 38.67 & 1800546 & 38.24 \\
\hline C3 & $\operatorname{TrC}$ & 1781935 & 10.73 & 1800546 & 10.59 & P3 & LE & 2825737 & 61.33 & 2908067 & 61.76 \\
\hline $\mathrm{C} 4$ & LC & 4567184 & 27.49 & 4660454 & 27.40 & & & & & & \\
\hline C5 & $\mathrm{RPC}$ & 6513815 & 39.21 & 6748946 & 39.68 & & & & & & \\
\hline C6 & $\mathrm{RC}$ & 148400 & 0.89 & 148400 & 0.87 & & & & & & \\
\hline
\end{tabular}

Table 3 Optimal and feasible results and CPU time for different problem sizes

\begin{tabular}{|c|c|c|c|c|c|c|c|c|c|c|c|c|c|c|c|c|}
\hline \multirow{2}{*}{$\begin{array}{l}\text { Sl. } \\
\text { No. }\end{array}$} & \multicolumn{8}{|c|}{ Problem size } & \multirow{2}{*}{ 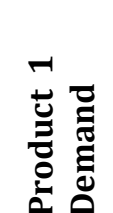 } & \multirow[b]{2}{*}{ 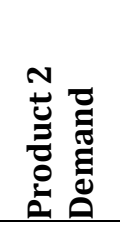 } & \multicolumn{2}{|l|}{ GP } & \multicolumn{2}{|l|}{ NGA } & \multicolumn{2}{|c|}{ Gap \% } \\
\hline & 1 & $\mathbf{p}$ & $\mathbf{a}$ & $\mathbf{n}$ & $\mathbf{r}$ & $\mathbf{w}$ & $\mathbf{x}$ & $\mathbf{y}$ & & & $\begin{array}{l}\text { Total Cost } \\
\text { (Rs) }\end{array}$ & $\begin{array}{l}\text { Total } \\
\text { Emission } \\
\text { (Kg) }\end{array}$ & $\begin{array}{l}\text { Total Cost } \\
\text { (Rs) }\end{array}$ & $\begin{array}{l}\text { Total } \\
\text { Emission } \\
\text { (Kg) }\end{array}$ & $\begin{array}{l}\text { Total } \\
\text { Cost }\end{array}$ & $\begin{array}{l}\text { Total } \\
\text { Emission }\end{array}$ \\
\hline 1 & 2 & 3 & 2 & 2 & 3 & 2 & 1 & 1 & 3000 & 2000 & 8542642 & 3048.2 & 8749374 & 3117.09 & 2.42 & 2.26 \\
\hline 2 & 5 & 3 & 2 & 2 & 4 & 2 & 1 & 1 & 6000 & 4000 & 16611335 & 4607.7 & 17008346 & 4708.61 & 2.39 & 2.19 \\
\hline 3 & 5 & 4 & 3 & 3 & 6 & 2 & 1 & 1 & 9000 & 6000 & 23459864 & 6154.8 & 24001787 & 6284.67 & 2.31 & 2.11 \\
\hline 4 & 7 & 4 & 3 & 3 & 8 & 2 & 1 & 1 & 12000 & 8000 & 31205685 & 7625.3 & 31889090 & 7780.86 & 2.19 & 2.04 \\
\hline 5 & 7 & 7 & 5 & 5 & 10 & 2 & 1 & 1 & 15000 & 10000 & 38965421 & 9145.7 & 39756419 & 9327.70 & 2.03 & 1.99 \\
\hline
\end{tabular}




\section{Conclusion}

In this paper, an MILP model was framed for a multi-objective CLGSC. The model is optimized using Goal programming and NGA. The relative importance of performance components is studied in detail. Logistics cost and purchase cost dominates the total cost and fixed cost and reprocessing cost does not contribute more. Similarly emission in the facilities contributes more in the total cost. The performance of NGA is better for complex problem it is clearly visible from the results obtained.

\section{Compliance with ethical standards}

\section{Disclosure of conflict of interest}

All authors declare that they no conflict of interest.

\section{References}

[1] Bektaş, T and Laporte, G. The pollution-routing problem. Transportation Research Part B: Methodological, 2011; Volume 45 (8):pp. 1232-1250.

[2] Bonney, M and Jaber, M Y "Environmentally responsible inventory models: Non-classical models for a nonclassical era", International Journal of Production Economics, 2011; Volume 133 (1):pp. 43-53.

[3] El Saadany, A M, Jaber, M Y, \& Bonney, M "How many times to remanufacture?" International Journal of Production Economics, 2013; Volume 143 (2): pp. 598-604.

[4] Ijomah, W L A model-based definition of the generic remanufacturing business process. 2002

[5] Kannan, G, Shankar, K M, \& Devika, K "Application of fuzzy analytic network process for barrier evaluation in automotive parts remanufacturing towards cleaner production- a study in an Indian scenario", Journal of Cleaner Production, 2016; Volume 114:pp. 199-213

[6] Krikke, H, le Blanc, I, \& van de Velde, S Product modularity and the design of closed-loop supply chains. California management review, 2004; Volume 46 (2):pp. 23-39.

[7] Kumar, S, \& Craig, S Dell, Inc.'s closed loop supply chain for computer assembly plants. Information Knowledge Systems Management, 2007; 6(3):197-214.

[8] Matar, N, Y Jaber, M, \& Searcy, C A reverse logistics inventory model for plastic bottles. The International Journal of Logistics Management, 2014; 25(2):315-333.

[9] McKinnon, A C, \& Piecyk, M I Measurement of CO 2 emissions from road freight transport: a review of UK experience. Energy policy, 2009; 37(10):3733-3742.

[10] Paksoy, T, Bektas, T, \& Ozceylan, E Operational and environmental performance measures in a multi-product closed-loop supply chain. Transportation Research Part E: Logistics and Transportation Review, 2011; 47(4):532-546.

[11] Paksoy, T, Ozceylan, E, Weber, G W, Barsoum, N, Weber, G W, \& Vasant, P “A multi objective model for optimization of a Green supply chain network", In AIP Conference Proceedings, 2010; Volume 1239, No. 1:pp. 311-320.

[12] Rashid, A, Asif, F M, Krajnik, P, \& Nicolescu, C M "Resource conservative manufacturing: an essential change in business and technology paradigm for sustainable manufacturing", Journal of Cleaner production, 2013; Volume 57:pp. 166-177.

[13] Ritchie, L, Burnes, B, Whittle, P, \& Hey, R "The benefits of reverse logistics: the case of the Manchester Royal Infirmary Pharmacy", Supply Chain Management: An International Journal, 2000; 5(5):226-234.

[14] Rogers, D T L, \& Tibben-Lembke, R S “RS Going backwards: reverse logistics trends and practices”, Reverse Logistics Executive Council. University of Nevada, Reno. Center for Logistics Management. 1998

[15] Santhosh Srinivasan and Shahul Hamid Khan "Environmentally conscious optimization of closed loop supply chain network with vehicle routing", Advances in Theoretical and Applied Mathematics, 2016a; Volume 11, Issue 3:pp. 223-243 
[16] Santhosh Srinivasan and Shahul Hamid Khan "Bi-objective Integrated Location-Allocation Planning in a Green Supply Chain Network Design", International Journal of Pure and Applied Mathematics 2016b; Volume 109, Issue 9:pp.99-107

[17] Santhosh Srinivasan and Shahul Hamid Khan "Designing and optimization of Closed Loop Supply Chain Network Design using Modified Shuffled Frog Leaping algorithm", International Journal of Pure and Applied Mathematics, 2016c; Volume 109, Issue 8:pp. 193-200

[18] Santhosh Srinivasan and Shahul Hamid Khan "Multi-stage manufacturing/re-manufacturing facility location and allocation model under uncertain demand and return" International Journal of Advanced Manufacturing Technology, 2018; Vol 94, Issue 5-8:pp 2847-2860

[19] Santhosh Srinivasan, Abhinav Kumar Sharma and Shahul Hamid Khan "Modeling and Optimization of Defective Goods Supply Chain Network with Heuristics", International Journal of Operations and Quantitative Management, 2016d; Vol 22, Issue 2:pp.177-187

[20] Vivek Kumar Chouhan, Shahul Hamid Khan, Mostafa Hajiaghaei-Keshteli and Saminathan "Multi-Facility Based Improved Closed-Loop Supply Chain Network for Handling Uncertain Demands ", Soft Computing, 2020; Vol 24, Issue 10:pp. 7125-7147.

[21] Wang, H F, \& Hsu, H W A closed-loop logistic model with a spanning-tree based genetic algorithm. Computers \& Operations Research, 2010; 37(2):376-389. 